\title{
The Effect of Open-Ended Approach on Automotive Electricity Learning in SMK Negeri 3 Makassar
}

\author{
Muhammad Komeini $^{1 *}$, Muhammad Yahya ${ }^{2}$, Purnamawati ${ }^{3}$ \\ ${ }^{123}$ Department of Vocational Education and Engineering, Universitas Negeri Makassar \\ Makassar, Indonesia \\ *Corresponding author's email: muhammadkomeini4566 [AT] gmail.com
}

\begin{abstract}
This study aims (1) to find out the students' capabilities in the closed-ended teaching method; (2) to find out the students' capabilities in the open-ended teaching method with a scenario; (3) to find out whether there is an effect of the open-ended teaching method with a scenario on the students' capabilities to solve automotive electrical system problems with problem-based scenarios. The research subject involved a whole class (consisting of 25 students) selected by the purposive sampling technique. The data were collected through observation, tests, interviews, and documentation, then analyzed with descriptive statistical analysis of percentages, frequency distribution tables and hypothesis testing with nonparametric statistical analysis, Mann Whitney test with SPSS-PC 20.0 for windows. The results of the data analysis showed that: (1) the students' capabilities to assemble an automotive electrical system (closed-ended teaching method) was $88 \%$, (2) the students' capabilities to solve automotive electrical problems with a problem-based scenario (open-ended teaching method in a scenario) was $72 \%$, (3) the effect of the students' capabilities in assembling electricity (closed-ended teaching method) was higher than the students' capabilities to solve electrical problems (scenario of open-ended teaching).
\end{abstract}

Keywords-Close-ended, automotive electrical capability, open-ended

\section{INTRODUCTION}

Vocational High School requires students to be competent in skills both in the form of technical skills (hard skills) and nontechnical skills (soft skills) so that students who are skilled in their field of expertise are needed. Efforts to improve the quality of education continue, but on the other hand, productive teaching tends to decline in terms of quality. One of the reasons productive teaching has declined is that productive teaching in schools is still carried out traditionally. Another reason that productive teaching in schools is hampered is that productive teachers still lack productive materials.

Based on the observations that have been carried out randomly on 30 students of competency in light vehicle engineering skills at SMK Negeri 3 Makassar, it is assumed to have passed the subject of Electrical Maintenance for Light Vehicles with a training learning model. It turns out that only $10 \%$ are declared able to solve problems with diagnostic skills (troubleshooting), which is good; the rest is identified as having difficulties providing answers to the test for solving Automotive Electrical problems.

Based on the explanation, there is an urge and desire to describe the extent to which the description of students' capabilities in the teaching and learning process is used when using a teaching method with a close-ended approach. They are assembling an automotive electrical system on an automotive electrical block panel with a job sheet guide, an open-ended approach teaching method with a scenario of the students' capability to solve damage problems in the automotive electrical circuit.

The open-ended learning method provides benefits, including encouraging students to have an independent perspective; encourage students to think harder; encourage students to develop Their experiments; makes learning more challenging; and make learning more active. This is also in line with the research of [1], which concluded that Open-Ended Learning (OEL) should focus on students who tend to explore less themselves because if students do less self-exploration, the students' ability to solve problems will be lower; vice versa, if students explore more themselves, the higher the ability of students to solve problems.

Thus the OEL model has an advantage over the conventional model in terms of achieving the learning outcomes of the 
Light Vehicle Engineering expertise package. So it can be said that the OEL model is effective in terms of achieving the learning outcomes of the Light Vehicle Engineering expertise package.

In the open-ended learning method, active students follow the learning steps that are in accordance with the syntax of the open-ended learning method. In addition, there was an increase in discussion activities both individually and in groups, collection of assignments, and the use of various learning resources. Thus, the open-ended learning method's application can increase students' activeness in learning the Light Vehicle Engineering expertise package. This is in line with the results of the study by [2], who concluded that OEL provides challenging learning opportunities; help automate and accelerate progress in learning; generate and solve its own challenges; allows solutions to switch objectives due to optimal challenges; shows creative potential; help explain its full potential; measure how big a new challenge is meaningful; enable the system to potentially create and solve endless compelling challenges; efficient for determining when to switch objectives from one problem to another; help better open problem search; allows a more definitive demonstration; more flexible to match environmental challenges; denotes open innovation that is suspended; and produces a variety of behaviours that solve environmental challenges, many of which cannot be solved by any other ways.

According to the constructivist view, the students will achieve learning goals if they actively build their knowledge in learning. Therefore, effectiveness is also influenced by the activities of students in learning. This is in line with the opinion of [3], which states that students learn the material better and can remember the concept of material longer. It was found that the students were accustomed to the assignments, answers and criteria that had been set. Their learning strategy tends to find the right answer. When the open-ended learning method is given to students in the vocational field, they will look for more indepth information, more focused learning. Still, students' tendency to emphasize more on single solution methods involves the instructor's role in providing guidance with clear procedures. It must be presented sequentially and make it easy for students to achieve competence.

The open-ended approach provides an opportunity for students to solve the problem. The open-ended approach can also control the level of students' capability to solve a problem. The open-ended approach provides opportunities for the emergence of new problems; thus, the open-ended approach offers a challenge for students to solve a problem so that it can improve students' capability to solve a problem. The open-ended approach can help teachers design curriculum materials that can improve students' ability to solve a problem [4].

\section{RESEARCH METHODS}

This research is quasi-experimental research. The research design used was a quasi-experimental non-equivalent control group design which can be seen in the image below:

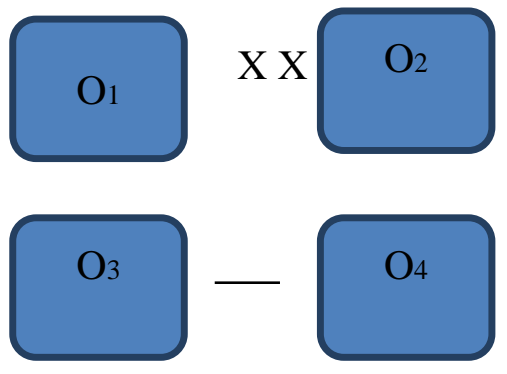

Fig. 1 Research design

Note:

$\mathrm{O} 1=$ Pretest of open-ended method with a scenario.

$\mathrm{O} 2$ = Posttest of open-ended method with a scenario,

O3 = Pretest of close-ended method

$\mathrm{O} 4=$ Posttest of close ended method

This study was in the automotive laboratory of SMK Negeri 3 Makassar, which is located on Jl. Bonto Te'ne No. 6 Makassar. The time for conducting this research is approximately three months, starting from April to July 2020. The population of the 
study was all students of the automotive study program consisted of 261 students.

Table 1. Number of Electricity Engineering Students in Academic Year 2020/2021

\begin{tabular}{|c|c|c|}
\hline No & Class & Number of Students \\
\hline 1 & $X$ & 108 \\
\hline 2 & $X I$ & 78 \\
\hline 3 & $X I I$ & 75 \\
\hline \multicolumn{2}{|c|}{} & Total \\
\hline
\end{tabular}

Source: The data of Student Principal of SMK Negeri 3 Makassar

The research subjects were 25 students of class XI, Electricity Engineering A of Academic Year 2020/2021, with a purposive sampling technique. The research variables are 1) independent variables; the closed-ended teaching method, namely combining with the open-ended teaching method with a scenario, namely solving electrical problems, 2) Bound Variables; capability to assemble and solve electrical problems. The independent variables are 1) The close-ended method, which is assembling the automotive electrical system, 2) The open-ended method, which is solving electrical problems. Bound variables are 1) the capability of students in assembling an automotive electrical system;2) the students' capability to solve automotive electrical system problems.

The techniques of data collection were 1) Observation, 2) Tests, 3) Interviews, 4) Questionnaires, 5) Documentation. The data analysis technique was nonparametric statistical analysis because of purposive sampling. Data analysis was performed by using descriptive statistical analysis of percentages, frequency distribution tables and testing the hypothesis by using the Mann Whitney test with SPSS-PC 20.0 for windows.

\section{RESULTS AND DISCUSSION}

\subsection{Students' capability in assembling electricity (close-ended).}

Table 2. Description of students' capabilities in assembling automotive electrical system with a job sheet guide through the electrical block panel learning media (close-ended).

\begin{tabular}{|c|c|c|c|}
\hline Category & Score & $\begin{array}{c}\text { Number } \\
\text { of } \\
\text { Students }\end{array}$ & Percentage \\
\hline Very capable of assembling an electrical system & $90-100$ & 7 & $28 \%$ \\
\hline Capable of assembling an electrical system & $75-89$ & 15 & $60 \%$ \\
\hline Incapable of assembling an electrical system & $<75$ & 3 & $12 \%$ \\
\hline Total of students & & 25 & $100 \%$ \\
\hline
\end{tabular}

1.2. Students' capability in solving automotive electrical problems (open-ended scenario).

Table 3. Description of students' capabilities in solving automotive electrical system problems with problem-based scenarios (open-ended scenario)

\begin{tabular}{|c|c|c|c|}
\hline Category & Score & $\begin{array}{c}\text { Number } \\
\text { of } \\
\text { Students }\end{array}$ & Percentage \\
\hline Very capable of solving problems & $90-100$ & 3 & $12 \%$ \\
\hline Capable of solving problems & $75-89$ & 15 & $60 \%$ \\
\hline Incapable of solving problems & $<75$ & 7 & $28 \%$ \\
\hline \multicolumn{2}{|c|}{ Total of Students } & 25 & $100 \%$ \\
\hline
\end{tabular}


1.3. The effect of the open-ended teaching method with a scenario based on the student's ability to solve automotive electrical problems.

Table 4. Mann-Whitney Test: the effect of the open-ended method with a scenario

\begin{tabular}{|c|l|l|l|l|}
\hline \multicolumn{7}{|c|}{$\begin{array}{c}\text { Mann-Whitney Test } \\
\text { Ranks }\end{array}$} \\
\hline \multirow{4}{*}{$\begin{array}{c}\text { Rank } \\
\text { Capabilities }\end{array}$} & \multicolumn{1}{|c|}{ N } & Mean Rank & Sum of Ranks \\
\cline { 2 - 6 } & Rank of Close Ended & 25 & 29.28 & 732.00 \\
\cline { 2 - 6 } & Rank of Open Ended & 25 & 21.72 & 543.00 \\
\cline { 2 - 6 } & Total & 50 & & \\
\hline
\end{tabular}

Table 5. Test Statistics

\begin{tabular}{|c|c|}
\hline Indicator & Automotive Electrical Capabilities \\
\hline Mann-Whitney $U$ & 218.000 \\
\hline Wilcoxon $W$ & 543.000 \\
\hline$Z$ & 1.868 \\
\hline Asymp. Sig. (2-tailed) & .002 \\
\hline \multicolumn{2}{|c|}{ a. Grouping Variable: Ranks } \\
\hline \multicolumn{2}{|c|}{ b. Not corrected for ties } \\
\hline
\end{tabular}

The conclusion is that the open-ended method has a significant effect with a scenario because of the significance value (2tailed) or asymp. sig. (2-tailed) the automotive electrical capacity of 0.002 is smaller than the significant level $(\alpha)$, which is 0.050 .

Table 6. Conclusions for hypothesis testing.

\begin{tabular}{|c|}
\hline Research hypothesis \\
\hline It is suspected that there is a significant effect on students' ability to solve electrical problems \\
using the open-ended method
\end{tabular}


Table 7. Description of the effect of student abilities with a scenario of closed-ended and open-ended teaching methods.

\begin{tabular}{|c|c|c|c|c|c|}
\hline \multirow{2}{*}{ Category } & \multirow{2}{*}{ Score } & \multicolumn{2}{|c|}{$\begin{array}{c}\text { Capabilities in } \\
\text { assembling electricity }\end{array}$} & \multicolumn{2}{c|}{$\begin{array}{c}\text { Capabilities in solving } \\
\text { problem of electricity }\end{array}$} \\
\cline { 3 - 6 } & & $\begin{array}{c}\text { Number } \\
\text { of } \\
\text { Students }\end{array}$ & Percentage & $\begin{array}{c}\text { Number of } \\
\text { Students }\end{array}$ & Percentage \\
\hline Very Capable & $90-100$ & 7 & $28 \%$ & 3 & $12 \%$ \\
\hline Capable & $75-89$ & 15 & $60 \%$ & 15 & $60 \%$ \\
\hline Incapable & $<75$ & 3 & $12 \%$ & 7 & $28 \%$ \\
\hline \multicolumn{2}{|c|}{ Total of students } & 25 & $100 \%$ & 25 & $100 \%$ \\
\hline
\end{tabular}

Table 8. The percentage table for the effect of students' abilities with the closed-ended and open-ended teaching methods is a scenario.

\begin{tabular}{|c|c|c|c|c|}
\hline $\begin{array}{c}\text { Approach to teaching } \\
\text { methods }\end{array}$ & $\begin{array}{c}\text { The number } \\
\text { of capable } \\
\text { students }\end{array}$ & $\begin{array}{c}\text { Percentage } \\
\text { of students, } \\
\text { capability }\end{array}$ & $\begin{array}{c}\text { The number } \\
\text { of } \\
\text { Incapable } \\
\text { students }\end{array}$ & $\begin{array}{c}\text { Percentage } \\
\text { of students, } \\
\text { incapability }\end{array}$ \\
\hline close-ended & 22 students & $88 \%$ & 3 students & $12 \%$ \\
\hline open-ended with a scenario & 18 students & $72 \%$ & 7 students & $28 \%$ \\
\hline
\end{tabular}

The closed-ended teaching method has a lower level of difficulty than the scenario of open-ended teaching because the closed-ended method: 1) has been designed in a structured manner, 2) involves problem-solving steps, 3) students are fully guided, 4) the method is designed to lead, 5) the instructor is actively involved, 6) more directed learning, 7) the tendency of students to use a single solution method, 8) more involving the role of the instructor, 9) presented sequentially, and 10) make it easy for students.

The incapability of students to assemble an automotive electrical system (close-ended) is due to 1) there is a tendency for students to memorize a series, 2) there is a tendency for students to depend on job sheets as a guide, and 3) there is a tendency for students to always be accompanied by an instructor.

The open-ended method with a scenario affects the student's ability to solve electrical problems. It just has a higher level of difficulty than the closed-ended teaching method because it is closer to solving the problem of damage to the automotive electrical system damage to the actual vehicle.

The effectiveness of using the open-ended method in the experimental class is higher than in the control class using the close-ended method. This finding is in line with the results of [5], which concluded that the open-ended method provides benefits, including encouraging students to have an independent perspective; encourage students to think harder; encourage students to develop their own experiments; makes learning more challenging; and make learning more active. This is also in line with [1] study, which concluded that the open-ended method should focus on students who tend to be less self-exploring. If students do not explore themselves a lot, their ability to solve problems will be lower. Contrarily, if the students explore more, the ability of students to solve problems will be higher. Thus the open-ended method has advantages over the closedended method in terms of achieving learning outcomes of the Light Vehicle Engineering expertise package. Thus, it is said that the open-ended method is effective in terms of achieving the learning outcomes of the Light Vehicle Engineering expertise package.

Another finding of this study is that in general active students follow the steps of learning in accordance with the openended method syntax. In addition, there was an increase in discussion activities both individually and in groups, collection of 
assignments, and the use of various learning resources. So that the application of the open-ended method can increase the activeness of students in learning the Light Vehicle Engineering expertise package, this is in line with the results of the study by [2], who concluded that OEL learning provides challenging learning opportunities; help automate and accelerate progress in learning; generate and solve its own challenges; allows solutions to switch objectives due to optimal challenges; shows creative potential; help explain its full potential; measure how big a new challenge is meaningful; enable the system to potentially create and solve endless compelling challenges; efficient for determining when to switch objectives from one problem to another; help better open problem search; allows a more definitive demonstration; more flexible to match environmental challenges; denotes open innovation that is suspended; and produces a variety of behaviours that solve environmental challenges, many of which cannot be solved by any other means.

According to a constructivist view, the students will achieve learning goals if they actively build their knowledge in learning. Therefore effectiveness is also influenced by the activities of students in learning. This is in line with the opinion of [3], which states that students learn material better, and can remember the concept of material longer. It was found that the students were accustomed to the assignments, answers and criteria that had been set. Their learning strategy tends to find the right answer. When the open-ended method problem is given to students in the vocational field, they carry out more in-depth information searches, more focused learning, but the tendency of students to emphasize more on single solution methods involves the role of the instructor in providing guidance with clear procedures and must be presented sequentially and make it easy for students to achieve competence.

The open-ended learning method utilizes problems. It is in line with [6] that the open-ended learning method utilizes problems that are formulated in such a way so as to provide opportunities for various kinds of answers with various strategies or their respective ways.

The open-ended learning method develops creatively. It is in line with [6] that the open-ended learning method helps develop creative activities and students' mindset through simultaneous problem-solving. Learning with an open-ended approach can train and foster originality of ideas, creativity, reason, cognitive, critical, openness and socialization.

The open-ended learning method helps independence, and this is in line with [7] that the open-ended approach allows humans and robots to acquire a growing list of skills independently. Thus, they can enable them to produce appropriate actions to achieve the desired effect in the environment. The open-ended approach encourages endless learning; enabling a contingency-based open-ended approach to occur; encourage the learning of motor skills that are used to achieve goals and internal representations of the results of actions.

The open-ended method with a scenario has several characteristics and advantages, namely: 1) emphasizes real problems, 2) emphasizes independence, 3) emphasizes the process of finding solutions, 4) emphasizes more on student exploration, 5) is more challenging and more meaningful, 6) the learning process is open so that students are more enthusiastic, 7) the learning concept is more effective because it is very contextual, encourages active student involvement in finding relationships between problems, 8) has the potential to develop student understanding, 9) encourages student involvement in practice, 10) encourages student involvement in designing discovery (discovery), 11) arouse curiosity, 12) practice problem-solving skills, and 13) into a meaningful experience and understanding.

The open-ended approach provides an opportunity for students to be able to solve a problem. This is in line with [4] research that the open-ended approach provides some advantages. It gives students opportunities to solve a problem, can control the level of students' capability to solve a problem, provides opportunities for the emergence of new problems, provides a challenge for students to be able to solve a problem. Thus, it can improve students' ability to solve a problem and help teachers design curriculum materials that can improve students' ability to solve a problem.

The open-ended approach can identify students' cognitive skills. This is in line with [8] research that the open-ended approach has several benefits. The benefits are including identifying students 'cognitive skills, using students' metacognitive strategies during learning and student problem-solving activities in an open learning environment. It can also interpret student learning behaviour further by mapping it to metacognitive strategies and developing and applying behaviour effectively.

The open-ended approach meets the real conditions in the field. This is in line with [9]'s research that the open-ended approach is closer to the real conditions in the field. The open-ended approach is very capable of measuring the level of students' knowledge in solving a problem. The open-ended approach is also precise, very easy to use and accurate and has a high degree of precision in measuring the level of students' ability to solve a problem. 


\section{CONCLUSIONS AND SUGGESTIONS}

Based on the results of research and discussion, it can be concluded that the capability of students to assemble an electrical system (close-ended) has a lower level of difficulty than the open-ended teaching method with a scenario. The students' ability to solve electrical system problems (open-ended with scenario) has a higher difficulty level. From the close-ended teaching method and the open-ended method with a scenario, there is an effect of students' capability to solve electrical problems. It only has a higher level of difficulty than the closed-ended teaching method because it is closer to solving the problem of damage to the automotive electrical system damage to the actual vehicle.

Suggestions for further research are that the teacher or instructor should use a real learning environment. The teacher or instructor should apply the open-ended teaching method with a scenario, still, first with the closed-ended teaching method. The teacher or instructor should make theoretical implications of the results of this study and for researchers. It is better to conduct further research on the effectiveness of the open-ended teaching method approach.

\section{REFERENCES}

[1] Alden Jack Edson, 2017. Learner- Controlled Scaffolding Linked to Open-Ended Problems in a Digital Learning Environment. ZDM 49, no. 5 (October 2017): 735-53, https://doi.org/10.1007/s11858017-0873-5.

[2] Askari, G., \& Kamarei, M., 2017. Windowing UWB Microwave, Mm-Wave Multi- Port S- Parameter Measurements Using OpenEnded Excess Electrical Length. The Journal of Engineering 2017(6): 257-259.

[3] Baldassarre, G., Mannella, F., Santucci, V. G., Somogyi, E., Jacquey, L., Hamilton, M., \& O’Regan, J. K. (2018). Action-outcome contingencies as the engine of open- ended learning: Computational models and developmental experiments. 2018 Joint IEEE 8th International Conference on Development and Learning and Epigenetic Robotics (ICDL-EpiRob), 46-53. https://doi.org/10.1109/DEVL RN.2018.8761035.

[4] Chongo, CN., Githua, B.N., Changeiywo, J.M. (2017). Effect of Open Ended Teaching Learning Approach On Secondary School Students' Mathematics Achievement In Learning Three Dimensional Geometry. International Journal Of Scientific and Technology Research Volume 6, Issue 12, Desember 2017. ISSN 2277-8616. IJSTR 2017. www.ijstr.org.

[5] Ichinco, M., \& Kelleher, C. (2019). Open-Ended Novice Programming Behaviors and their Implications for Supporting Learning. IEEE Symposium on Visual Languages and Human- Centric Computing (VL/HCC). 45-53. Memphis, TN, USA: IEEE, 2019. https://doi.org/10.1109/VLHC C.2019.8818886.

[6] Jangali, S. G., \& Gaitonde, V. N. (2020). Attaining competencies in Programme Outcomes through Open-Ended Experiments. Africa Education Review, 17(1), 116-140. https://doi.org/10.1080/181466 27.2018.1481757

[7] Kasaei, S.H., Tome, AM., \& Lopes, LS. (2019). Hierarchical Object Representation for Open- Ended Object Category Learning and Recognition. 930th Conference on Neural Information Processing Systems (NIPS 2016), Barcelona, Spain IEETA - Instituto de Engenharia Electrónica e Telemática de Aveiro University of Aveiro, Averio, 3810-193, Portugal.

[8] Kinnebrew, JS., Segedy, JR., \& Biswas, G., 2014. Analyzing the Temporal Evolution of Students' Behaviors in Open-Ended Learning Environments. Metacognition and Learning 9, no. 2 (August 2014): 187-215. https://doi.org/10.1007/s11409- 014-9112-4.

[9] Riadi, Muchlisin. (2019). Model Pembelajaran Open Ended Learning. (on line),( https://www.kajianpustak a.com/2019/03/model- pembelajaran-open ended- learning.html), diakses 27 November 2019.

[10] Wang R., Lehman J., Stanley KO. (2020). Enhanced POET: Open-Ended Reinforcement Learning through Unbounded Invention of Learning Challenges and their Solutions. Published on Mar 19, 2020. in arXiv: Neural and Evolutionary Computing. 